Session 2158

\title{
A Masters of Technology degree using a combination of Synchronous and Asynchronous digital learning delivery modes.
}

\author{
Dr. Kamal F. Bichara, Dr. A. Raj Chowdhury \\ Kent State University, School of Technology
}

\begin{abstract}
:
Kent State University's School of Technology houses a diversity of degree programs spanning over a wide variety of curricular areas including Engineering, Aeronautics, Industrial Technology, Business Technology and Computer Technologies. The School of Technology through the Kent State eight campus system serves the educational and training needs of business, industry and manufacturing sectors covering a large geographical area in northeast Ohio. A recent assessment needs survey indicated a strong demand for a flexible " practitioner based" graduate degree program designed primarily to impact "life-long" learning of the workforce involved in the areas of manufacturing, quality assurance, electronics, automation and computer systems.

This paper describes the methodology used in the development, implementation and delivery of a Master of Technology (MT) degree via "Distance Learning (DL)" mode using a combination of Web based, compressed video teleconferencing and web enhanced tools for course delivery. The techniques used to accommodate learners from a variety of background and academic preparation through the use of web resident computer based training modules incorporating animation and speech instructions as well as actual, simulated or virtual laboratory experiments will be discussed.
\end{abstract}

\section{Master of Technology Degree at Kent State University: An Introduction}

The emerging field of engineering science and technology is impacting the technology-based curriculum in the $21^{\text {st }}$. century higher education. Technology literacy and "life-long" learning has become an essential part of the millennium work environment. This is especially evident in Ohio, where the Ohio Board of Regents is promoting a rapid transformation of the state's education system that will impact economic development, workforce development and Ohio's global competitiveness.

According to the Chancellor of the Ohio Board of Regents Roderick G.W. Chu, knowledge is the key source of economic growth and higher education institutions must help Ohio's employers meet their immediate needs for knowledge workers and move aggressively to encourage young Ohioans to pursue careers in the knowledge-based industries ${ }^{1}$. Charged with the Ohio Board of Regents Access and Success Challenge ${ }^{2}$, the School of Technology at Kent State University has 
successfully integrated its technology curricula providing a seamless access from certificate to associate to baccalaureate and master of technology degree throughout the Kent State's eightcampus system. Challenged by the new competition created by technology as a tool, the School of Technology has structured its curriculum through an innovative approach to teaching and learning, competency based skill development, distance and distributive learning, and a practitioner based degree programs aimed at impacting the knowledge-based economy.

\section{Master of Technology Degree Overview}

In an effort to provide easier access to high quality, technology-based education, Kent State University's School of Technology provides academic programs in a variety of contemporary technology fields. The School's Master of Technology (MT) degree allows students to develop a comprehensive approach to the technology discipline with specializations in the following $\operatorname{areas}^{3}$ :

- Computer and Information Technology

- Quality Systems and Reliability Engineering

- Industrial and Production Management

- Electronics and Digital Control Systems

- Automated manufacturing

- Aeronautics and Aviation Technology

- Technology Education

The Master of Technology can be viewed as an interdisciplinary degree (Figure 1) providing the needed competencies to serve engineering, business and technology disciplines and/or sectors.

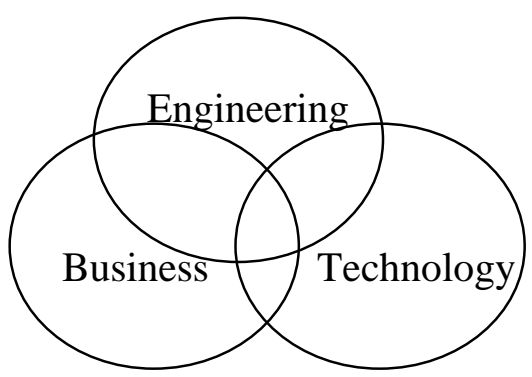

FIGURE 1

A Curriculum Synergy in the Master of Technology

Degree at Kent State University

The greatest strength in the MT-degree program is the "program flexibility" which allows the students to complete the graduate level courses via the World Wide Web, computer assisted instruction and V-Tel /video teleconferencing. Given the rapidly changing technologies and its impact on required skills/working knowledge in every field, and the diverse needs of emerging career trends, this flexibility has been and continues to be important to meet the required human resource development needs of the state of Ohio. 


\section{Master of Technology Degree Requirement}

The School of Technology at Kent State University provides a practitioner based curriculum model with a seamless transition from Certificate to Associate to Bachelor of Science to Master of Technology degrees. This is designed to promote continuous impro vement, skill development and life-long learning for the technology-based workforce.

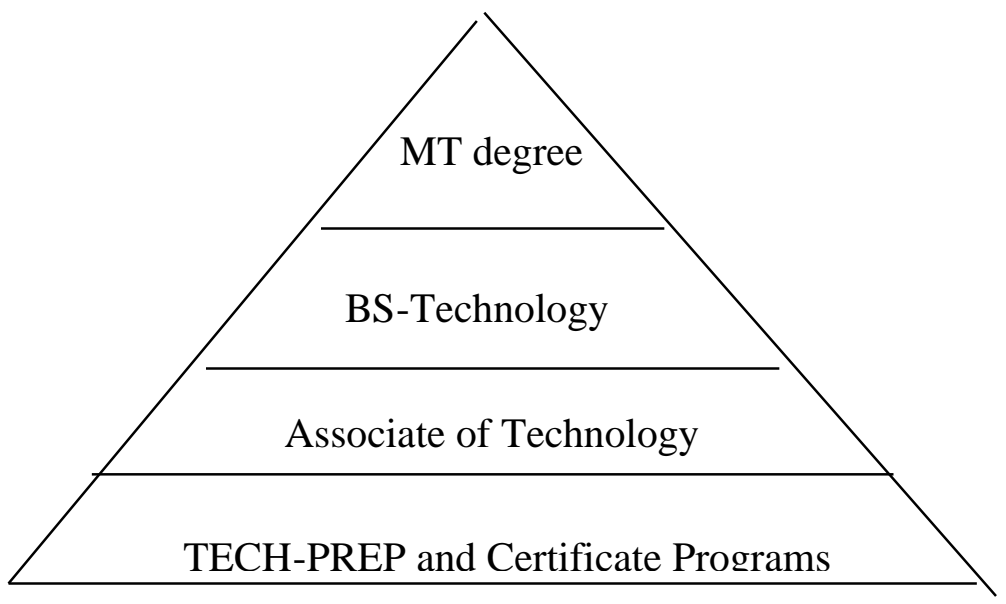

FIGURE 2

Technology Curriculum Model at Kent State University

Student pursuing a Master of Technology (MT) degree must complete a minimum of 32 graduate credit hours. At least 16 of those hours must be the School of Technology (TECH) courses at the 60000 (post-undergraduate) level and above. The students must also satisfy three (3) core course requirements, which are:

$\begin{array}{ll}\text {-TECH 50000 } & \text { Quality Standards } \\ \text {-TECH 60000 } & \text { Project Management } \\ \text {-TECH 60078 } & \text { Research in Technology }\end{array}$

The core courses are designed to provide required competencies in applied research, operational and quantitative skills in a technology environment. The degree program offers both a thesis and non-thesis option. The thesis option is recommended for students interested in in-depth research, development and advanced post-graduate studies in a specific technical area of interest. The nonthesis option is suggested for students who seek a more general curriculum for advanced technical coursework for career development. Therefore the Master of Technology (MT) degree template has the following minimum credit hour requirements:

$\begin{array}{ll}\text {-Core Courses } & 9 \text { semester hours } \\ \text {-Technical Specialization } & 15 \text { hours } \\ \text {-Elective Course work } & 2-3 \text { hours } \\ \text {-Thesis/ Non-thesis option: } & 6 \text { hours }\end{array}$

Proceedings of the 2002 American Society for Engineering Education Annual Conference \& Exposition. Copyright $\odot$ 2002, American Society for Engineering Education 


\section{Role of synchronous and asynchronous modes of course delivery:}

Distance Learning (DL) and the distributive mode of instructional delivery should be viewed as a "life-long" learning and re-engineering tool with regard to location and time of course delivery. Therefore, it seems obvious that, DL-based education must play a key role in developing and implementing the Master of Technology degree program. Kent State University has embraced the broad and rich possibilities of distance learning as its core institutional activity supplementing the standard on campus teaching and research.

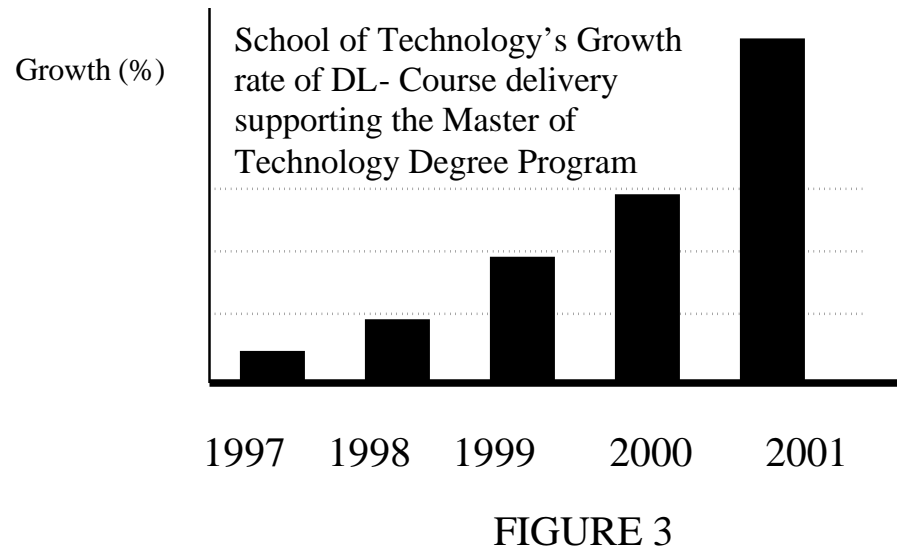

Providing the integrated eight-campus access to the Master of Technology (MT) course work and with the depth of expertise required in several content areas, the graduate faculty in the School of Technology has adopted a system wide expertise and an industry based knowledge to package the content delivery. Since AY 1999-2000, the School has progressively offered courses from the "virtual experts" via a variety of asynchronous and synchronous delivery modes (i.e.: web based, web enhanced, I-Linc and V-Tel). This has ensured the students, regardless of their location, to pursue the MT degree and even complete the course requirements via the DL mode. The DL access and the innovative approach have assisted the non traditional students to complete their graduate degree and continue their careers in the wired $21^{\text {st }}$. century.

\section{Delivery of actual laboratory hands-on experience in an asynchronous web environment}

The fast evolution of the Internet and the World Wide Web in the late 1990's resulted in increased interest in the use of the Internet asynchronous methods for delivery of both credit and non-credit courses. Success was reported from various institutions around the country in the implementation of graduate and undergraduate courseware. These efforts were focused on topics of a theoretical nature where lecture notes and simple explanations supplemented by hyperlinks to sites offering reference material for the subject matter were judged to be adequate.

The review of the web-based courses currently available on the web and those reported by various institutions of higher education reveals that in some disciplines, like electronics and computer engineering and technology, a severe limitation played a major factor in the course 
design for web delivery. This limitation is the difficulty in providing laboratory hands-on experience to support the theoretical part of the course in areas like electronics and microprocessors and control systems. While several software simulation programs are now available, many educators still feel, as we do, the need for hands-on practical experience as an integral part of a graduate course in engineering and technology.

In this paper, we report on the design and delivery of a web-based course in Information Systems \& Automation in Industry (TECH64012) that incorporates the following components:

1. Support modules for both the theory and lab components in a multimedia environment using computer animation, graphic illustrations and human speech.

2. A laboratory component that utilizes a Motorola MC68HC11 micro-controller based CME11E9-EVBU development board.

3. A digital prototyping system designed by the author to provide all needed bias levels, hardware and input/output timing clock signals required for interface/prototyping and design of external circuits

4. Software simulation and development tools.

5. A complete web-based course offering easy access to course calendar, chat sessions, on-line quizzes, midterm exams and bulletin board using the WebCT development program.

\section{Course Design}

The developed course in Information Systems \& Automation in Industry (TECH64012) is a graduate course which may be taken by students following the Electronics, Manufacturing or Computer options of the Master of Technology degree program.

The web-based course offers hyperlinks to access information on the course and its administration, the instructor, course syllabus, laboratory experiments, lecture and lab notes, training modules, course updates, course calendar, grading policy, online quizzes and chat sessions.

The training modules supporting the lecture, lab notes and the laboratory experiments include modules that were developed using Macromedia Authorware Attain. The modules incorporate various multimedia components to facilitate the learning process.

In order to access these modules, students are informed the first time they select one of the hyperlinked modules that a plug-in module for the Macromedia web player is required. The program then proceeds to download the plug-in which is installed automatically.

The components include animated illustrations, high-resolution graphics, and human speech. The course delivery has been tested using Netscape 4.7, 6.2 and Internet Explorer 5 with a screen graphics resolution optimized at $800 \times 600$. 
The following computer-based training modules are available to students with navigational tools allowing them to control the pace and format of the module viewing:

- 68HC11 Microcontroller board

- Adv. Programming Techniques

- DL1414 Display Module

- A-to-D Interface Board

- Input/Output Board

- Liquid Crystal Display Module

- Peripheral Interface Adapter

- Keypad Interface

- Input/Output capture board

- D/A and A/D Conversion

\section{Laboratory Experiments}

In this component of the course design, a great deal of effort was expanded to produce a course where hands-on laboratory practice is not compromised. The laboratory tools that are made available to the students are:

The Motorola CME11E9-EVBU development board.

The hardware prototyping system developed by the author named "TuscTronics".

Ten (10) custom designed interface boards covering twenty four (24) lab experiments of varying complexity

A kit of all parts and wiring required for the experiments.

A digital multi-meter.

A logic probe.

\section{Course Project}

In addition to the weekly lab experiments, all students are required to design, construct and report on an original project dealing with a micro-controller application in an automation and/or control application. For the purpose of illustration, we will discuss the design and construction of the TuscTronics prototyping system.

\section{The TuscTronics Trainer}

The TuscTronics trainer represents an original design of a reliable self-sufficient system for the breadboarding of a digital circuit with moderate complexity. The trainer includes full wiring, switching, output monitoring capability, clocking for up to eight (8) 16-pin integrated circuits. It includes the following:

- (4) Logic switches (SW0-SW3) 
- (2) Momentary push-button switches; PB4, PB5 and their complements

- Regulated Vcc, Gnd, logic 1 posts near each of the eight IC sockets

- A low variable frequency TTL ranging from DC to $200 \mathrm{Hertz}$

- Easy wire connections through (160) of approximately 1 inch height springs

- (4) Light emitting diode indicators wired as common cathode.
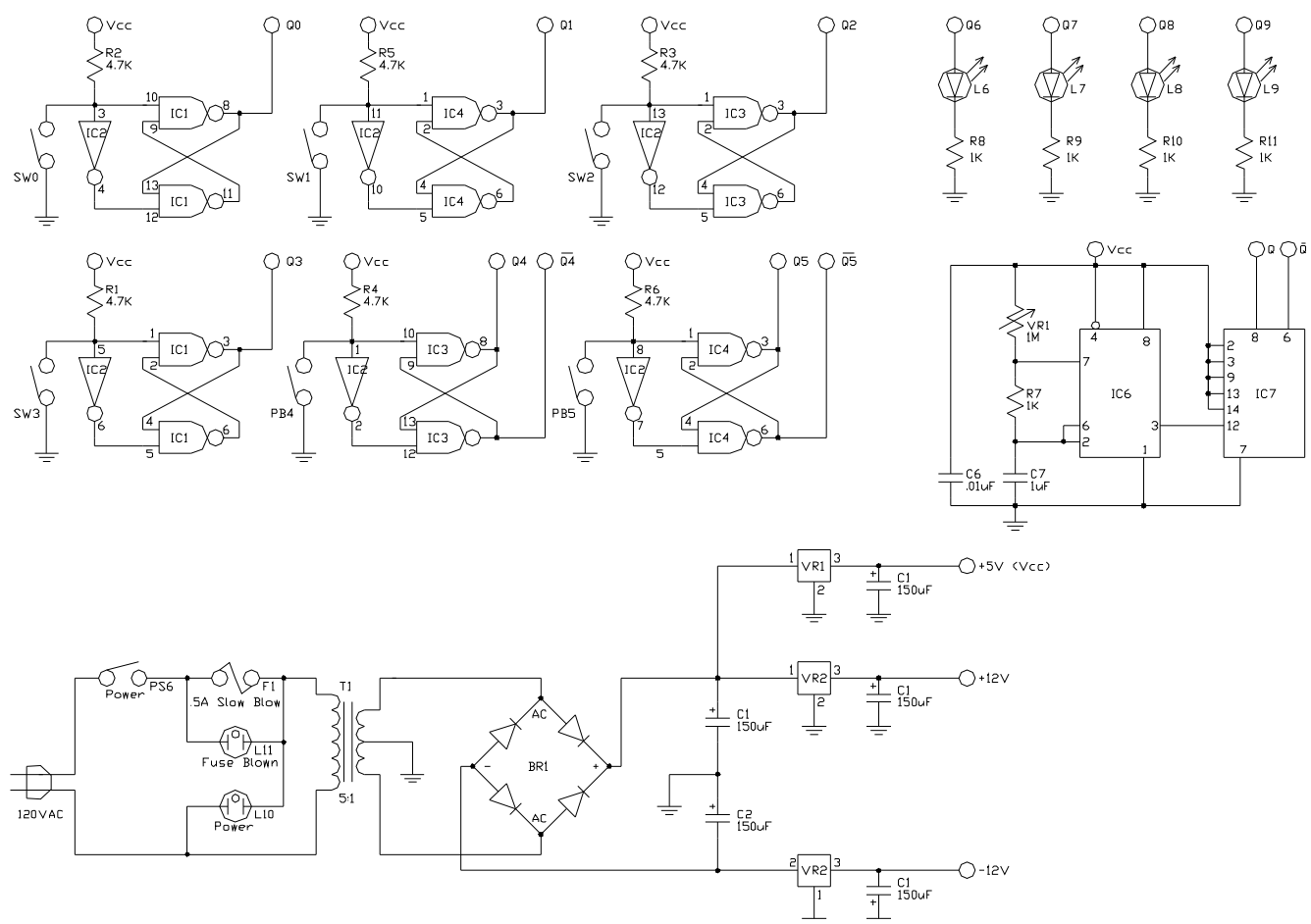

FIGURE 4

Schematic diagram for the TuscTronics prototyping system

\section{Conclusion}

Now in its third year of offering, the DL based Master of Technology at Kent State University has proven its viability in meeting the educational and training needs of graduate technology students. During the fall semester of 2001, One hundred and three students were enrolled in the MT program.

The successful design and delivery of all of the required and elective (concentration area) courses using the web and compressed video teleconferencing modes made it possible for graduate students with varying learning and scheduling needs to effectively progress through the program. 
The creative solutions achieved to provide uncompromised hands-on laboratory experience operating in an environment using the world wide web as the sole delivery mode, makes it possible to incorporate hardware type courses with a meaningful practical design focus.

Not withstanding some minor adjustments to the course calendar and related scheduled activities, the delivery of the course with the planned laboratory setup has proven to be successful thus far. Considering a first time offering during the spring 2000 semester, it is safe to say that the course delivered in this mode is meeting its objectives. While there are no comparatives to illustrate variance in student achievements compared to an in-person class instruction, student success as measured by their semester grade and through the evaluation of their course project, support the conclusion that the laboratory and theory parts of the course are well-received by students who have completed the course.

1. Chowdhury, A. R. " Kent State University School of Technology: Leading the way through the 21st.Century", Journal of Industrial Technology, Volume 14, No. 3, summer, 1998.

2. Ohio Board of Regents: Statement on Access and Success Challenge (http://www.regents.state.oh.us)

3. Kent State University 2001-02 Graduate Catalog and School of Technology Website (http://www.tech.kent.edu)

DR. KAMAL F. BICHARA, Professor, School of Technology, Kent State University, Kent, Ohio 44242, USA.

Kbichara@Tusc.Kent.Edu

DR. A. RAJ CHOWDHURY, Professor and Dean, School of Technology, Kent State University, Kent, Ohio 44242, USA.Raj@Tech.Kent.Edu 